\title{
PREVALENCE OF PAIN AND ASSOCIATED FACTORS IN BRAZILIAN CIVIL SERVANTS: AN INTRODUCTORY ANALYSIS USING BASELINE DATA FROM THE ELSA-BRASIL COHORT
}

Luciana Andrade Carneiro Machado (Faculdade de Medicina - Hospital das Clínicas - UFMG, Belo Horizonte, MG, Brasil), Rosa Weiss Telles (Faculdade de Medicina - Hospital das Clínicas - UFMG, Belo Horizonte, MG, Brasil), Isabela Benseñor (Hospital Universitário da Faculdade de Medicina Universidade de São Paulo, São Paulo, SP, Brasil), Sandhi Maria Barreto (Faculdade de Medicina Hospital das Clínicas - UFMG, Belo Horizonte, MG, Brasil)

\section{BACKGROUND}

In Brazil, the prevalence and costs of pain will increase substantially with population ageing. Understanding of pain epidemiology is needed for the development of health care policies that can minimize this projected burden. The objective was to investigate the prevalence of pain and associated factors at baseline of the Brazilian Longitudinal Study of Adult Health (ELSA-Brasil).

\section{MATERIALS AND METHODS}

Data were collected in universities/research institute located in six state capitals (2008-2010). Information on the presence of any pain/discomfort and pain/discomfort subjectively attributed to psychological distress (pain/discomfort 'with psychological attributions' - PPA) was retrieved from the section on somatic symptoms of the Clinical Interview Schedule-Revised (CIS-R). Questions about characteristics of the symptomatic episode were answered only by the subsample with PPA. The $x 2$ test of independence investigated associations between sociodemographic/clinical factors and the presence of each symptomatic episode (overall sample) and chronicity (subsample with PPA). The investigated sociodemographic/clinical factors were age group (35-44, 45-54, 55-64, 65-74), sex (male, female), race/ethnicity (Black, Brown, White, Asian, Indigenous), social class (low, middle, high), work status (active or retired), nature of occupation (manual, routine non-manual, non-routine non-manual), body mass index - BMI (eutrophic $<25 \mathrm{~kg} / \mathrm{m} 2$, overweight $25-29.9 \mathrm{~kg} / \mathrm{m} 2$, obese $\geq 30 \mathrm{~kg} / \mathrm{m} 2$ ), physical activity, smoking, excessive drinking, depressive/anxiety symptoms, sleep disturbance, diabetes, and previously diagnosed cardiovascular disease and arthritis/rheumatism. Sensitivity analyses excluded discomfort from the case definition.

\section{RESULTS}

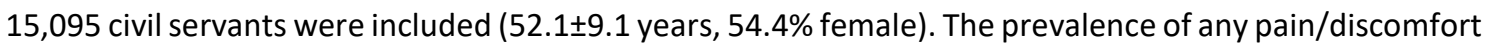
and PPA was $72.0 \%(95 \% \mathrm{Cl} 71.3 \%-72.7 \%)$ and $26.0 \%(95 \% \mathrm{Cl} 25.3 \%-26.7 \%)$, respectively. Among those with PPA, $57.5 \%$ had chronic symptoms ( $\geq 6$ months), $55.1 \%$ perceived their symptoms as bothersome during activity, and $33.2 \%$ had symptom-related negative affect. Symptomatic episodes were associated with all sociodemographic/clinical factors investigated $(p \leq 0.001)$, except for race/ethnicity, smoking and cardiovascular disease (any pain/discomfort), and body mass index (PPA). In those with PPA, chronicity was associated with sex, social class, nature of occupation, anxiety, sleep disturbance and arthritis/rheumatism. When only the report of pain (excluding discomfort) was considered, the prevalence of symptoms dropped slightly: $62.4 \%$ had any pain $(95 \% \mathrm{Cl} 61.6-63.2)$ and $22.8 \%$ had PPA $(95 \% \mathrm{Cl} 22.2-23.5)$. Results of sensitivity analyses on associations were mostly similar.

\section{CONCLUSION}

This study provided preliminary information on the epidemiology of pain at baseline of the largest Latin American cohort on chronic non-communicable diseases. Future longitudinal analyses in ELSA-Brasil will allow the clarification of the underlying mechanisms responsible for the associations observed in the present study. 